\title{
História pública e cinema: o filme Chico Rei e o conhecimento histórico
}

\author{
Public history and cinema: \\ the movie Chico Rei and historical knowledge
}

Rodrigo de Almeida Ferreira

A inter-relação entre história e indústria cinematográfica é recorrente. Acontecimentos do passado ou episódios do tempo presente frequentemente são abordados pela sétima arte seja em gêneros ficcionais, seja em documentários. Os avanços tecnológicos ocorridos a partir da década de 1970, desde o advento do videocassete até a popularização dos formatos digitais característicos deste milênio, fizeram com que a audiência de filmes, incluindo aqueles com temáticas históricas, crescesse consideravelmente, chegando ao espaço privado e se popularizando como prática pedagógica. ${ }^{1}$

Rodrigo de Almeida Ferreira é mestre em História e doutor em Educação pela UFMG, integra os grupos de pesquisa do CNPq História e Audiovisual (ECA/USP) e do Centro de Pesquisa em História da Educação (FAE/UFMG), e é professor do Centro Universitário (dealmeidarodrigo@gmail.com)

Artigo recebido em 30 de junho e aprovado para publicação em $1^{\circ}$ de setembro de 2014 .

Est. Hist., Rio de Faneiro, vol. 27, no 54, p. 275-294, julho-dezembro de 2014. 
Não obstante, são reconhecidas as críticas, especialmente feitas por acadêmicos, às películas lançadas nessa seara, sobretudo quanto a imprecisões históricas e abordagens superficiais e vulgares do passado. Inerente a esse cenário, permanece presente a pergunta sobre a relação entre o cinema e a história, ou seja, sobre a maneira como a história tem sido abordada nessas adaptações fílmicas e qual o seu impacto no tocante ao conhecimento histórico.

Pensar o filme com temática histórica ultrapassa, portanto, a ideia de correção ou equívoco do produto cinematográfico diante das pesquisas históricas. Esse tipo de filme não apenas abordará um tema do passado, mas também poderá funcionar como mediador, divulgador e produtor do conhecimento histórico. A narrativa fílmica sobre a história traz consigo um potencial educativo, que pode vir a ser utilizado tanto no espaço escolar quanto no ambiente não escolar.

Considera-se, sob essa perspectiva, que os chamados filmes históricos ${ }^{2}$ estão circunscritos à prática da história pública, tanto pelo seu viés de divulgador da história como também de produtor do conhecimento histórico. Assim, toma-se esse gênero fílmico e sua perspectiva educativa a partir da análise dos imaginários sociais (Baczko, 1985) presentes nos filmes, construídos na interface entre a historiografia e outros campos narrativos, como a literatura, a música e o carnaval.

As reflexões que se seguem visam a problematizar a circularidade do conhecimento histórico sob o viés das representações históricas realizadas pelo cinema, haja vista a relevância das produções audiovisuais nessa relação. A análise se fará na perspectiva do conceito de história pública, tomado em interface com os filmes históricos, tendo como referência Chico Rei, dirigido por Walter Lima Júnior e lançado em 1985.

Como será abordado adiante, Chico Rei narra a história de Galanga, um rei africano que teria sido escravizado e enviado para a região aurífera do Brasil do século XVIII. Na região das Minas, rebatizado com o nome cristão Francisco, Galanga obteve sua liberdade, chegou a se tornar proprietário de uma mina de ouro e conseguiu alforriar outros companheiros de cativeiro, estabelecendo laços de solidariedade e autoridade. Ainda que a história de Chico Rei seja uma lenda, a trama apresentada está contextualizada no período do Brasil português. A película de Walter Lima Júnior, portanto, favorece reflexões sobre o cinema e a história pública, uma vez que se trata de uma produção artística em diálogo com a historiografia e outras áreas que representaram Chico Rei e seu universo. Sua narrativa cinematográfica, ao apresentar a temática para os espectadores, passa a ser significada historicamente, além de poder viabilizar práticas pedagógicas escolares tendo como tema, por exemplo, a sociedade mineira colonial e o escravismo. 


\section{O cinema e a história pública}

A apropriação de acontecimentos históricos pelo filme remete à invenção do cinema e ao desenvolvimento da linguagem cinematográfica. Não é objetivo aqui retomar o estabelecimento desse diálogo entre a história e a sétima arte. Não obstante, vale destacar alguns pontos dessa relação para melhor dimensionar as interseções entre o cinema, a história pública e o conhecimento histórico.

Um primeiro ponto refere-se à resistência que apresentaram os historiadores a incorporar em seu trabalho o filme de abordagem histórica. Em síntese, a base dessa desconfiança remonta ao conflito inerente à representação fílmica e à ideia de veracidade histórica. O entendimento de Boleslas Matuszewski, que trabalhou com os irmãos Lumière, de que "o cinematógrafo não dá talvez a história integral, mas pelo menos o que ele fornece é incontestável e de uma verdade absoluta" (Matuszewski apud Kornis, 1992: 240) dá o tom dessa tensão.

O processo de produção fílmica, então, mereceu relevantes reflexões, estabelecidas ainda na década de 1920, que questionavam a intencionalidade de um filme por meio das escolhas e da montagem. ${ }^{3}$ Todavia, o entendimento do cinema como imagem-verdade, como expressado por Matuszewski em 1898, perdurou - e ainda se faz presente - sobretudo na esfera do senso comum. A tensão decorrente da percepção do filme histórico como algo entre verdade objetiva e subjetividade (Napolitano, 2005), quer dizer, ou como um testemunho imparcial ou como a recriação ficcional do passado, é um dos fatores que explicam a hesitação dos historiadores em incorporar o filme em suas pesquisas.

Outro aspecto a ser destacado é a aproximação dos historiadores do universo fílmico, verificada de modo mais consistente a partir da década de 1960. Atribui-se a Marc Ferro o mérito pelo estabelecimento do diálogo entre os historiadores e o cinema, devido ao seu artigo "O filme: uma contra-análise da sociedade?". ${ }^{4}$ Ferro defende a elaboração de uma metodologia para explorar a relação cinema-história, já que o filme, independentemente do gênero, pode ser lido como uma contra-análise da sociedade, uma vez que a imagem ultrapassa os significados cinematográficos. Assim, o cinema se torna um documento do tempo presente, sendo possível para o historiador identificar no filme elementos para compreender a sociedade para além das representações operadas pelos grupos dominantes, pois, para o autor, o filme pode romper os controles existentes sobre a sua produção, tanto externos quanto internos (Ferro, 1992: 86).

Desde então, o cinema ganhou espaço entre os historiadores no exercício de seu ofício. Contemporaneamente, destaca-se a percepção que procura analisar as representações fílmicas e suas implicações para a sociedade entendendo o filme para além de uma fonte para os estudos históricos. Michele Lagny, talvez o nome de maior ascendência dessa linha, tem promovido reflexões que visam a 
constituir o cinema como um objeto na historiografia, imprimindo análises sob perspectiva teórica, em diálogo tanto no campo da história quanto no campo dos estudos de cinema e da história do cinema (Lagny, 1997).

Relembrar esses pontos na tensionada relação do historiador com o cinema é pertinente para se perceber que, se por um lado o filme tem sido apropriado pelos historiadores em suas pesquisas e trabalhos educativos, por outro lado permanecem sombras que cobram fidedignidade a uma suposta verdade objetiva. Quer dizer, à parte a cumplicidade atual entre historiadores e filmes históricos, conflitos em torno da autoridade da produção do conhecimento histórico podem emergir, como exemplificado nos bastidores da série televisiva canadense People's history (2000), sobre a história do país. Apesar de contar com historiadores na produção, estes não tinham poder de decisão, mesmo quando os planos de filmagem contradiziam suas pesquisas. Questionado sobre o fato, Gordon Henderson, produtor da série, ratificou a decisão, concordando que a história, "de fato, era mais complexa do que nós [a tv] a representamos, mas se nós desejamos falar sobre uma história, eu não quero dizer 'por um lado' e 'por outro lado"' (Friesen, 2011: 196), e criticando o formalismo da linguagem corrente entre historiadores acadêmicos.

Esses conflitos não retiram a crescente relevância do filme na representação e problematização do passado. Considerando-se o papel cada vez mais central da imagem em nossa sociedade, Robert Rosenstone reconhece no filme de gênero histórico uma destacada maneira de se representar o passado:

Filmes, minisséries, documentários e docudramas históricos de grande bilheteria são gêneros cada vez mais importantes em nossa relação com o passado e para o nosso entendimento da história. Deixá-los fora da equação quando pensamos o sentido do passado significa nos condenar a ignorar a maneira como um segmento enorme da população passou a entender os acontecimentos e as pessoas que constituem a história (Rosenstone, 2010: 17).

O autor não subestima a tradição histórica escrita, mas propõe pensar a escrita da história por meio de outros suportes. Ciente de que o sentido histórico da sociedade não é produzido mais exclusivamente pelas páginas escritas, Rosenstone reconhece que o significado histórico de um filme é distinto do saber historiográfico e, por isso, as análises sobre as narrativas históricas impressas e cinematográficas precisam levar em conta suas peculiaridades. Aliás, reservadas as particularidades existentes entre autores/escolas, referentes ao cinema-história, tem-se como princípio que um filme é um filme, uma produção artística e comercial; não um trabalho produzido segundo os ditames acadêmicos. 
Diante desse cenário, acredita-se que equívocos e cobranças que permearam a relação cinema-história possam ser evitados ao se abordar a relação história pública e cinema. Tal cuidado precisa ser adotado especialmente por duas características da história pública. A primeira é sua preocupação em divulgar o conhecimento histórico para além dos portões universitários, alcançando um público mais amplo e não especialista ${ }^{5}$ - algo que exige o deslocamento do discurso tradicional acadêmico para outros tipos de linguagem. A segunda característica é a sua produção transdisciplinar. Isso não implica, contudo, a desqualificação da ciência histórica em favor da emergência da história pública. Antes o contrário: quanto maior for o leque de áreas pesquisando de modo reflexivo o passado e promovendo a divulgação dessas pesquisas, mais ampla será a circularidade do saber histórico, favorecendo o desenvolvimento da cultura histórica entre não acadêmicos. Sob esse prisma,

a história pública é menos sobre "quem" ou o "que", e muito mais sobre "como". Nem tanto um substantivo, principalmente um verbo. A história pública tem importância real e urgente, dada a crescente popularidade das representações do passado nos dias de hoje. Em um contexto de segmentação acadêmica e profissionalização restrita, os agentes da história pública podem fornecer uma mediação necessária, inspiradora e revigorante entre o passado e seus públicos (Liddington in Almeida \& Rovai, 2011: 50).

A história pública tem como características o compromisso social, político e educativo, o favorecimento do acesso às informações e a divulgação do conhecimento histórico, como observam Chalhoub \& Fontes (2009). Todavia, acredita-se que a história pública ultrapassa a difusão da história. Trata-se de uma produção problematizada sobre o conhecimento histórico que mobiliza áreas, saberes e linguagens distintas, ainda que a narrativa histórica não seja realizada por um historiador de ofício. Isso não significa abrir mão do rigor da produção historiográfica, mas sim considerar a produção do conhecimento histórico em diálogo com outras áreas, não necessariamente acadêmicas. Ou seja, pensar na perspectiva de coprodução, algo como uma autoridade compartilhada (Frisch: 1990).

Nesse sentido, reivindica-se o papel do filme de temática histórica como articulador de elementos de uma equação que configura a cultura histórica, qual seja: o saber histórico acadêmico, o conhecimento histórico social (circulante na oralidade, literatura, iconografia, livros didáticos etc.) e a narrativa cinematográfica propriamente dita sobre o tema. 
A realização de um filme sobre história exige da produção fílmica o uso de uma ou mais fontes com pontos de identificação histórica, delas se apropriando e/ou as ressignificando, o que permite uma construção narrativa que estimule a reflexão, ou mesmo que crie novos significados. Impõe-se, nesse sentido, a reflexão de Paul Ricoeur (2010) sobre a construção da narrativa histórica, entendida entre o quase ficcional e a quase realidade, para se analisar a narrativa cinematográfica da história. Essa dinâmica termina por estabelecer a circularidade de conhecimentos, que podem ou não ser corroborados pela produção acadêmica.

O filme de Walter Lima Júnior é profícuo para se pensar esse processo dialógico, já que a história lendária do Chico Rei circulou desde as tradições populares e em diversos suportes (poesia, literatura, carnaval, cinema), para então se fazer presente em livros escolares e receber a atenção de historiadores em produções acadêmicas (Ferreira, 2014). Percebe-se, pois, que a circularidade do conhecimento histórico diz respeito não somente à existência das narrativas históricas (acadêmicas ou não), mas fundamentalmente à influência que uma narrativa pode exercer sobre uma nova abordagem que, além de revalidar o conhecimento corrente, possa promover uma redefinição pontual ou profunda, ressignificando conhecimentos sobre um determinado fato histórico. Essa circularidade é fundamental para o estabelecimento da história pública e, consequentemente, da educação para o conhecimento histórico - dentro e fora do espaço escolar.

\section{Chico Rei e a circularidade do conhecimento histórico}

Para analisar como o filme Chico Rei pode servir para se pensar o papel do cinema e outras áreas na construção da história pública e na circularidade do conhecimento histórico, faz-se necessário entender como a história do Chico Rei se tornou corrente na memória coletiva.

Conforme assinalado, não há registros oficiais referentes ao negro Galanga, ou Chico Rei. No entanto, é possível reconhecer sua presença no imaginário popular desde o período da escravidão, sobretudo por dois aspectos. O primeiro diz respeito à luta e à resistência negra contra a escravidão não pela violência e/ou a fuga, mas lançando mão de táticas inerentes ao próprio sistema escravista, como a aquisição da alforria. Essa característica era para o diretor Walter Lima Júnior um diferencial na história que ele filmava em relação a uma abordagem predominante da história da escravidão brasileira, conforme declarou à imprensa por ocasião do centenário da abolição e quando seu filme foi exibido na Sessão da tarde, pelo canal Globo de televisão: 
Na verdade, Chico Rei é um mito que não atinge a consciência nacional como Zumbi dos Palmares, que eu, particularmente, acho totalmente enganoso, já que passa um sentimento separatista e de derrota. Chico Rei, ao contrário, é um mito da conciliação, onde o negro usa o próprio sistema, tirando proveito dele e fazendo a sua liberdade (Correio Brasiliense, 13/05/1988: 32).

O segundo aspecto recai na memória festiva ligada às tradicionais congadas, remanescentes da América portuguesa. No período colonial, as irmandades religiosas negras realizavam os festejos em homenagem ao seu santo de devoção criando uma corte real. Essa inversão na sociedade escravista, quando os negros se tornavam rei e rainha, era tolerada e, de certo modo, era necessária para a manutenção da ordem nas cidades, vilas e arraiais (Ramos, 1996; Boschi, 1986). $\mathrm{O}$ fato é que permanece corrente associar a coroação do rei negro à lenda de Chico Rei (Souza, 2002).

A permanência desse imaginário pode ser constatada na peça Maracatu Chico Rei, composta por Francisco Mignone e executada pela primeira vez em outubro de 1934. Apesar de a tradição popular ter sido inscrita no espaço da música clássica, a perspectiva heróica e folclórica sobre o rei negro perduraria. A permanência é perceptível também nas letras, como no poema Romanceiro da Inconfidência, publicado pela poetisa Cecília Meireles em 1953.

O carnaval também representou essa história. A escola de samba carioca Acadêmicos do Salgueiro desfilou o enredo O sonho dourado de Chico Rei, conquistando o vice-campeonato de $1964 .{ }^{6}$ Composto por Geraldo Babão, Djalma Sabiá e Binha, e interpretado pelo Noel Rosa de Oliveira, o samba enredo reiterava os elementos da narrativa popular e literária.

Somente em 1966 um novo viés para a história se estabelece, com o romance histórico de Agripa Vasconcelos, Chico Rei. ${ }^{7}$ Vale destacar a apresentação na orelha da primeira edição:

Para escrever este livro, o autor não se limitou - como seria perfeitamente lícito ao ficcionista - a imaginar situações mais ou menos plausíveis, em que a figura de Chico Rei fosse muito mais simples ficção do que, como de fato ocorreu, uma pessoa que realmente existiu, e, mais do que isso, uma pessoa que foi mesmo o que os menos informados afirmavam tratar-se de pura lenda. Ao contrário, descendo "às raízes do assunto", conseguiu Agripa Vasconcelos reunir material suficiente para demonstrar que a sua história tem muito mais de realidade do que de lenda: é, inequivocamente, História, com maiúscula. 
Neste convite ao leitor, é latente o conflito entre a verdade objetiva e a lenda a respeito de Chico Rei. Ao autor são reconhecidos os méritos por fazer conhecer uma história pautada em documentação - embora suas referências sejam imprecisas - e mostrar que as liberdades ficcionais não são aleatórias. É significativa a aposta da editora de que, a partir do romance histórico, “o legendário rei africano também irá tornar-se tema obrigatório de discussões, tanto na província literária como no terreno dos historiadores".

Lendária ou calcada em evidências históricas, a trama do Chico Rei circulava entre as memórias de comunidades mineiras, de literatos, de historiadores e mesmo de foliões carnavalescos. A heroicização do Chico Rei é compreensível diante da realidade escravocrata presente na maior parte da história brasileira. O protagonista dessa história se tornava um exemplo de inteligência, dignidade, resistência e coragem, mesmo nas condições mais adversas. Elementos valorizados para um roteiro de cinema.

Antes de analisar algumas representações da história em Chico Rei, deve-se destacar, ainda que sinteticamente, dois aspectos da história dessa produção fílmica. O primeiro é que se trata de uma produção estimulada pela Embrafilme, que, em parceria com o Ministério da Educação e Cultura, lançou em 1977 o programa Filme Histórico. O projeto previa também recursos para séries televisivas nessa temática.

A ação da Embrafilme estimulava a produção cinematográfica e a divulgação de aspectos histórico-culturais brasileiros, dentro da ideia de um cinema educativo. Não obstante, o projeto também revelava um viés ideológico ao visar a afirmação de aspectos de uma identidade nacional, conforme se constata no telegrama emitido pelo presidente da entidade, Roberto Farias, às associações regionais de cinegrafistas:

Com esse programa o Ministério objetiva não só promover o reencontro do público brasileiro com a riqueza temática de sua história, mas também produzir obras que contribuam para maior elevação do nível artístico-cultural do nosso cinema, mantendo simultaneamente ponderável índice de comunicabilidade. ${ }^{8}$

O programa Filme Histórico foi bem recebido pelos cineastas, pois afinal era uma possibilidade de ter projetos viabilizados pelo financiamento estatal. ${ }^{9}$ Dos 74 projetos inscritos, dos quais 18 foram aprovados (Ferreira, 2014: 155-171), dois propunham filmar a história de Chico Rei.

Com um projeto inconsistente, a proposição da produtora NTM foi indeferida. A outra proposta foi apresentada pela StopFilm, representada por Jor- 
ge Bodansky. Diferente do material da NTM, percebe-se maior cuidado no projeto inscrito pela StopFilm. A ideia inicial era realizar um filme e uma série televisiva. A justificativa reiterava o papel emblemático do protagonista, pois,

como figura histórica, Chico Rei engloba uma parte importante da história nacional, abrangendo o período que se convencionou chamar de ciclo do ouro, com a incipiente cultura nacional, a integração das raças, o sincretismo religioso, danças, folclore, música e costumes que depois viriam a constituir a base da cultura brasileira. ${ }^{10}$

O processo trazia o orçamento detalhado, e nas etapas de execução previa-se que, "enquanto os pesquisadores, o historiador e o fotógrafo estiverem realizando os respectivos levantamentos de campo, o roteirista irá catalogando o material e esboçando o roteiro, sob a coordenação do diretor de produção e o controle da produtora". A boa perspectiva comercial era essencial para a defesa do projeto, pois a produtora garantia que, após aprovação no Brasil, poderia finalizar negócios no exterior, já que havia realizado sondagens reais de colocação do filme/seriado no mercado internacional.

A presença de um historiador na equipe revela cuidados com a pesquisa e a função educativa do filme. Contudo, a preocupação comercial do projeto torna legítimo questionar a autonomia desse profissional, pois a produtora parecia considerar os dados históricos um risco para o sucesso do filme e da série, já que intencionava

realizar um filme histórico de ação e aventura, com suficientes atrativos para o mercado exibidor mundial. Pretende-se colocar nos episódios informação suficiente para retratar os fatos históricos relacionados com a figura de Chico Rei, sem que com isto venha a ser prejudicada uma linguagem cinematográfica capaz de despertar as atenções do grande público. ${ }^{11}$

A sinopse dos 13 episódios da série foi assinada por Mário Prata. A apresentação dos personagens revela o excesso de liberdade poética: Chico Rei, Tiradentes, Marília de Dirceu, Tomás Gonzaga, Aleijadinho estão no cenário. Os títulos dos episódios também dão essa dimensão, ${ }^{12}$ revelando que a cronologia e os acontecimentos da história do Brasil seriam parcialmente respeitados.

Walter Lima Júnior foi contatado para assumir a direção do projeto, mas se incomodou com o excesso de adaptações no roteiro original, pois o resultado 
pervertia parte da memória nacional. Quase uma década depois do lançamento de Chico Rei, o diretor assim relembrava seu primeiro contato com o projeto:

Chico Rei tinha sido muito diferente do que me fora oferecido até então, alheio a todo o esquema que eu havia vivido até ali. Fui procurado por uma produção estrangeira, da TV alemã, e convidado para fazer esse filme: me deram o roteiro para eu ler, era uma série de TV escrita por um autor de novela chamado Mário Prata. Eu não conhecia o trabalho dele. Li, gostei de muitas coisas, mas não concordei com muitas outras que ele pôs no roteiro, principalmente com a liberdade que ele tomava com personagens muito emblemáticos de nossa História. No meu entender, aquilo era uma espécie de "samba do crioulo doido". Ele misturava Chico Rei com Tiradentes, fazia uma bagunça. Achei uma maluquice, estava mexendo com o inconsciente nacional. Então propus aos alemães mudar a história, tirar tudo aquilo, que aí eu faria o filme, e reescrevi o roteiro. Eles me permitiram (Revista Quadro a Quadro, 1994: 26).

Percebe-se o entendimento de Walter Lima Júnior quanto ao cinema-história como mediador do conhecimento histórico, exigindo, portanto, que o trabalho de direção fosse realizado com cuidados redobrados e respeito a uma produção especializada. $\mathrm{O}$ diretor reescreveu o roteiro, suprimindo os excessos, mas mantendo parte da estrutura original.

O segundo aspecto da história do filme começa justamente a partir da aprovação do projeto pela Embrafilme. Por um adendo ao contrato, assinado no ano seguinte (27 de agosto de 1978), a Provobis, representante de um grupo televisivo alemão, associava-se à StopFilm como produtora. ${ }^{13}$

Desentendimentos entre os produtores e a Embrafilme começaram a acontecer, sobretudo quanto ao descumprimento de prazos. Os produtores alemães reivindicavam alterar o roteiro, indignando Mário Prata, para quem "os alemães tinham sua própria visão dos fatos (interessava-lhes somente o aspecto exótico) e começaram a fazer uma série de objeções e exigências entre as quais uma participação maior da Embrafilme" (O Estado de São Paulo, 4/3/1980: 17).

A relação foi-se deteriorando até que, em fevereiro de 1980, as filmagens que aconteciam em Ouro Preto foram interrompidas com a saída da Provobis, que reivindicava o direito sobre todas as latas de filmes. Walter Lima Júnior acionou a Justiça e conseguiu impedir que se fizesse um leilão dos negativos e que eles saíssem do Brasil. A Embrafilme concordou em socorrer a produção e terminar as filmagens, financiando também a montagem e sonorização. Mas o processo foi desgastante e lento, sendo concluído somente em 1985. 
Como se pode inferir, foi um trabalho exaustivo, com muitas pendências judiciais e econômicas. Além das questões financeiras, é possível perceber as divergências entre o filme idealizado pelo diretor e a produção. Pensada inicialmente para ser uma minissérie, cujas filmagens resultariam no filme, a montagem foi identificada pela crítica como o maior problema de Chico Rei, pois o farto material filmado (aproximadamente 17 horas de copião) precisou ser condensado em 115 minutos no longa-metragem (Revista Visão, 26/08/1987: 22).

Concluído todo esse processo, o filme entrou em circuito comercial. Chico Rei se apresentava ao espectador como um filme histórico logo na sua abertura, quando uma cartela assim explicava a escravidão negra africana no Brasil: "Durante três séculos perto de dois milhões de africanos foram transportados como escravos para o Brasil colonial português. Destituídos de qualquer direito, trabalhando sem descanso, e com um curto período de vida, os negros tudo fizeram para manter viva sua fé na liberdade".

Na sequência, outra cartela referenciava os embasamentos utilizados para a construção do roteiro: "Baseado em argumento de Mário Prata; na tradição oral mineira; na poesia de Cecília Meireles e na memória do negro brasileiro". Nos créditos finais, o recurso da cartela explicativa era retomado com o título "Fontes Essenciais de Consulta", sendo citados livros de referência sobre a história da escravidão e o texto de Agripa Vasconcelos. ${ }^{14}$

As três cartelas revelam a preocupação em construir uma narrativa fílmica balizada. Por elas se percebe a confluência de três tipos de fontes: $\left.1^{\mathrm{a}}\right)$ a historiografia referente à escravidão, com destaque para o viés marxista, como predominava nos anos 1970; $2^{\mathrm{a}}$ ) o romance-histórico, nomeadamente o trabalho de Agripa Vasconcelos, que, conforme visto, reivindicava a pesquisa em sua narrativa; e $3^{\mathrm{a}}$ ) a memória, sustentada na oralidade e em práticas culturais, especialmente as relativas à população negra. A inter-relação dessas tipologias permite inferir que, apesar da preocupação com as fontes, a produção do filme não criou uma hierarquia entre elas, uma vez que conviviam trabalhos acadêmicos, literários e a tradição oral mineira.

As sequências iniciais indicam a tônica da representação fílmica sobre a história da escravidão e a luta dos negros pela liberdade. Os planos de abertura revelam uma abordagem da história do Brasil marcadamente crítica ao sistema colonial e ao escravismo.

À primeira cartela segue-se um plano aberto que acompanha três negros acorrentados correndo. A câmera passa por cima de uma pedra, quando aparece o título Chico Rei acompanhado de música, e então os braços dos negros surgem escalando essa pedra. Em meio à segunda cartela e aos créditos iniciais de atores, os negros são focalizados quebrando as correntes que os unem. Nenhuma palavra é dita, apenas um primeiro plano em suas faces sorridentes. Segue-se um pla- 
no aberto, preenchido por uma paisagem montanhosa, onde negros constroem muros de pedras, fortificados com paliçadas. É o quilombo, cujo significado para os escravos ultrapassava o local de refúgio de cativos, pois trazia a ideia de liberdade (Reis \& Gomes, 1996).

Para o espectador, o significado dos planos parece claro, ainda que ele nunca tenha ouvido falar de quilombo. Esse procedimento lírico segue uma convicção do diretor ao filmar: "Não se coloca na boca tudo o que você quer dizer. Deve-se deixar que o público sinta, pois ele entende a linguagem e o diretor também. Há uma cumplicidade". ${ }^{15}$

A sensibilização do espectador para o drama da escravidão negra prossegue no plano que se desenvolve no quilombo. A câmera acompanha Kindere, um negro que veio para o Brasil junto com Chico Rei. Andando lentamente pelo quilombo, ele observa seus companheiros em atividades cotidianas, como o reforço dos muros de pedra ou um batuque com dança de capoeira. Então, o quilombola, cuja sobriedade ratificada pela posse de um cajado lhe confere a autoridade do saber, assume a função de griot (contador de histórias nas tribos africanas). Walter Lima, cujas fontes estão assentadas no campo da memória e da tradição, reconhece a importância desse tipo de personagem nas sociedades tribais africanas fazendo dele o narrador da história de Chico Rei. A estrutura narrativa do filme integra o griot à trama, o que evita o excesso de voz over e os flashbacks. A narrativa de Kindere é por vezes compartilhada com o próprio personagem de Chico Rei e, em outros momentos, com o padre espanhol.

Sentado com o apoio de seu cajado e mirando o horizonte, Kindere inicia a narrativa por meio de um jargão próprio dos contadores de histórias: "Há muito tempo atrás, havia um rei chamado Galanga. Grande herói da batalha de Maramara. E esse reino era de todos os negros do Congo. Meu e de todos vocês". Estabelece-se, assim, a cumplicidade entre o narrador-espectador-história.

A complexa relação inerente ao escravismo levou o diretor de Chico Rei a procurar as origens desse sistema. Quando Kindere inicia narrativa, a sequência é cortada para o plano de uma construção antiga em que se destaca uma cruz ao alto. A legenda "África, meados do século XVIII" localiza o espectador, enquanto um movimento de câmera lento e descendente revela o pátio onde negros e negras de todas as idades estão amontoados, acorrentados e desorientados, sendo vistoriados por mercadores de escravos e observados por padres impassíveis diante do caos estabelecido. Trata-se de um depósito onde negros recém-capturados eram negociados e mantidos em quarentena até seu embarque para o Brasil. Nesse cenário, o representante do mercado anuncia a outros comerciantes que havia negros conhecedores de mineração e, também, que nobres haviam sido capturados: trata-se do rei Galanga e sua família. Um padre espanhol, que em breve demonstrará crise de consciência, transita entre os desafortunados prisio- 
neiros e asperge água benta sobre todos ao realizar um batismo compulsório, bradando seus novos nomes cristãos: Maria! Francisco!

A travessia em navios negreiros, popularmente conhecidos como tumbeiros, é um dos momentos de maior ação no filme. Ainda que Galanga não tenha existido de fato, milhões de negros foram arrancados da Africa e transportados para a América em navios europeus. No filme, o tema circula à luz de variadas fontes. Apesar de vários cortes, é notório o embasamento no livro de Agripa Vasconcelos para a sequência marítima. A iconografia oitocentista sobre o transporte em navio, o desembarque e os leilóes nos mercados de escravos também está presente.

A sequência África-travessia marítima colabora para conformar um conhecimento histórico que, ao ser problematizado, oferece ao espectador a educação relativa ao escravismo e ao tráfico negreiro. Em Chico Rei as cenas no tumbeiro contêm os problemas possíveis em alto mar: péssimas condições de acomodação; fome e sede; sadismo dos carcereiros; revoltas; estupros; tempestade; assassinato em massa. Mas há que se destacar a dignidade e serenidade do protagonista mesmo diante das dificuldades. Ciente da intensidade e importância dessa sequência, Walter Lima Júnior considerara a parte "inicial do filme, até a chegada deles [negros] à cidade de Ouro Preto, até a venda dos escravos, uma das melhores coisas que eu fiz no cinema". ${ }^{16}$

O filme apresenta uma questão de fundo na narrativa de Galanga/Chico Rei: a liberdade. Como o diretor afirmou em entrevista a Wilson Cunha, "a liberdade é prática dialética vivida no cotidiano - a mim me parece que este é o verdadeiro sentido desta lenda na alma do povo. Foi assim que eu a senti, e é assim que eu tento me expressar a partir do filme" (Fornal do Brasil, 23/08/1987: 24).

Walter Lima Júnior segue esse princípio à risca. Durante as filmagens, a bordo da escuna que servia de locação para a travessia dos escravos, o diretor realizou leituras públicas da obra Os condenados da terra, propondo uma discussão sobre questões da negritude junto ao enorme grupo de figurantes, negros em sua maioria e com baixa escolaridade. Segundo o diretor, ele não tencionava doutrinar ninguém, apenas "devolver a eles aquilo que é deles". ${ }^{17}$ As leituras parecem ter surtido efeito, já que parte desse grupo educado na escuna seguiu para Ouro Preto e, quando houve a ruptura com a Provobis, a maior parte dele demonstrou consciência da importância do trabalho desenvolvido para a história e a identidade negras, dando apoio à equipe de produção. Vislumbra-se, sob essa perspectiva, a possibilidade formativa do cinema não apenas quando o filme é exibido, mas em sua própria produção.

No campo da História, o filme coloca a questão da liberdade na escolha entre a resistência violenta ou a paciência em aproveitar as brechas da própria sociedade escravista. No primeiro caso, se ganha com a rapidez da ação, mas sem- 
pre se corre risco ao violentar seu senhor e fugir rumo a um quilombo - situação representada na sequência de abertura do filme. No segundo caso, o cativo deve aceitar o ônus da escravidão, a autoridade do seu senhor e, assim, se beneficiar de um tratamento menos agressivo até o ponto de conseguir a alforria, ou seja, a liberdade jurídica. Este foi o caminho adotado por Galanga. No entanto, a complexidade da decisão é apresentada em vários momentos do filme, a começar pela opção de Galanga/Chico Rei de buscar a liberdade via brechas na própria sociedade, enquanto seu filho, Muzinga, opta por fugir para o quilombo.

Um acalorado debate sobre o significado da liberdade se passa no quilombo, quando um representante da Irmandade do Rosário chega ao local para convencer Muzinga a retornar para a vila e obter, junto com o pai, a alforria. Como argumento, o irmão do Rosário questiona se de fato era livre aquele que vivia em fuga, já que o quilombola poderia ser recapturado a qualquer momento por um capitão-do-mato. Muzinga, como porta-voz dos quilombolas, entendia que a liberdade dos negros ia além de usar correntes e argolas. Tratava-se, para os quilombolas, de uma liberdade interna. Por isso desconsideravam a alforria, pois, uma vez obtida, o negro deveria conviver dentro das regras da sociedade branca. Mantendo essa posição, o filho de Galanga permanece no quilombo, enquanto o emissário retorna para Vila Rica.

Um filme com temática histórica se propõe abordar o tempo passado. Mas, como destaca Marc Ferro (1992), esse tipo de filme também revela fatos do momento em que é realizado. Essa ponte temporal, pela qual o passado é usado à guisa do presente, pode ser realizada inconscientemente ou deliberadamente.

Em Chico Rei, por exemplo, a luta dos escravos pela liberdade no século XVIII dialoga com a mobilização dos brasileiros pelo fim da ditadura militar imposta em 1964. O filme começou a ser rodado em 1979, em meio à Lei da Anistia, e foi concluído em 1985, após a campanha das Diretas Já. A luta contra a ditadura levantou discussões sobre as melhores maneiras de derrotá-la, polarizadas entre as opções pela luta armada ou as mobilizações civis visando a ocupar os espaços institucionais. Seria legítimo pensar a luta armada como a solução quilombola? Na mesma toada, considerar que a liberdade definitiva, representada pela democracia, necessitaria da negociação? Parece que sim - Walter Lima Júnior considera que, apesar do protagonista do seu filme não ser tão celebrado quanto Zumbi ou Chica da Silva, "Chico Rei é mais denso e politicamente mais consequente" (O Globo, 23/08/1987: Segundo Caderno, 1).

Outras passagens fornecem elementos que configuram a relação tempo passado/tempo presente, como as emblemáticas sequências de violência e abuso do poder legal metropolitano sobre a população. Em uma dessas representações, o Major Seixas, proprietário de Chico Rei, é preso e torturado. O governador e o capitão militar, responsáveis pela prisão e castigos, condicionam a liberdade de 
Seixas não apenas ao silêncio relativo à tortura sofrida, mas à atribuição dos ferimentos a uma queda sofrida quando tentava fugir da prisão. Destaca-se, nesse diálogo, a fala do governador de que a memória pessoal não é a memória oficial, o que revela as disputas em torno da memória e sua historicização quando elaborada em narrativa (Paul Ricoeur, 2010).

Estabelecendo novamente a ponte para o tempo presente: a tortura ao Major Seixas não seria uma denúncia da violência repressiva que adotava a tortura e o desaparecimento de opositores da ditadura? Parece pertinente o paralelo entre a situação do proprietário de Chico Rei com o traumático episódio da morte do jornalista Vladimir Herzog em 1975, ${ }^{18}$ que terminou por reforçar os argumentos pró-abertura política. Como salienta o diretor, é "interessante que um filme como um gesto histórico suscite outro gesto histórico". ${ }^{19}$ Chico Rei, como outros filmes com temática histórica, permite esse duplo movimento: a divulgação do conhecimento histórico e a reflexão sobre o tempo presente.

\section{Considerações finais}

A interface entre o filme histórico e a história pública não se restringe a recriar acontecimentos passados na linguagem audiovisual. É essencial considerar que, ao se debruçar sobre o passado, o diretor e o roteirista, bem como o elenco, partem de um saber existente - que pode ser da história ou do campo ficcional, como por exemplo o caso do lendário Chico Rei. Ao estabelecer o diálogo com outras narrativas - históricas ou ficcionais - sobre o tema a ser filmado, ocorre a ressignificação de variados aspectos. $\mathrm{O}$ filme, portanto, não apenas retomará o conhecimento já circulante, mas produzirá uma narrativa cinematográfica sobre os acontecimentos passados.

As nuances do filme com temática histórica evidenciam o dinamismo da sua produção em história pública, quando conhecimentos históricos em variadas narrativas são retomados e se estabelecem novas construções narrativas. As tensões entre as versões narrativas sobre o tema são importantes e devem ser consideradas, mas para além da dicotômica oposição entre verdade objetiva $x$ subjetividade. Acredita-se que o essencial é estabelecer uma ponte entre a reflexão sobre as narrativas históricas - produzidas por acadêmicos e não acadêmicos - e as maneiras de divulgação e problematização dessas pesquisas como movimento de circularidade do conhecimento histórico, logo, também, educativo.

Por essa via, destaca-se a relação sobre a história pública e o cinema de temática histórica como uma prática da educação escolar por favorecer o trabalho orientado pelo professor. Mas, também, de educação não escolar, já que o fil- 
me histórico se constrói a partir dos diálogos entre a historiografia e o conhecimento histórico disseminado entre a população - cuja circularidade ocorre por diversos mediadores -, delineando uma influência mútua na conformação de imaginários sociais e culturais e o cinema-história. Nesse sentido, pontos de referência da memória histórica são reforçados e/ou recolocados pela filmografia.

1. Entre a vasta produção relativa ao uso do filme no processo educacional escolar destacam-se o trabalho pioneiro de Serrano e Venâncio Filho (1931) e as produções mais contemporâneas de Napolitano (2008) e Duarte (2009).

2. Segue-se a proposição de José Maria Caparrós Lera, que define três tipos de filmes históricos: $1^{\circ}$ ) aquele com valor histórico ou sociológico, mas que não tem intenção de ser uma representação histórica; $2^{\circ}$ ) aquele de gênero histórico, que se sustenta em acontecimentos históricos, porém sem se ater a uma rigorosa reconstituição; $3^{\circ}$ ) aquele com intencionalidade histórica, cujo objetivo é representar um acontecimento, sendo elaborado com maior rigor em termos acadêmicos (Lera, 1997).

3. Destaca-se nessa discussão, sobretudo, o grupo de cineastas russos composto entre outros por Lev Kulechov, Sergei Eisenstein e Diziga Vertov (Aumont, 2004; Saraiva in Mascarello, 2008).

4. O artigo integrou a coleção História: novos problemas, novas abordagens, novos objetos, dirigida por Jacques Le Goff e Pierre Nora, lançada originalmente em 1974.

5. A Universidade de Oxford, graças aos esforços do professor Raphael Samuel, fundou em 1976 o History Workshop Fournal, sendo pioneira nesse processo. Nos
Estados Unidos, Robert Kelley, docente na Universidade da California (Santa Bárbara), instituiu um curso de pós-graduação pensando na atuação de historiadores nos setores público e privado para além do ensino. $\mathrm{Na}$ mesma universidade californiana, Kelley lançou em 1978 a revista The Public Historian.

6. O Salgueiro novamente apresentava um tema da história popular e do negro, tendo sido campeão em 1963 com o memorável desfile narrando a história da ex-escrava Chica da Silva (Ferreira, 2011: 217; Ferreira, 2014: 81-87).

7. Lançado pela editora Itatiaia, o livro integra a coleção Saga no país das Gerais, composta por seis títulos, todos de autoria de Vasconcelos: Fome em Canaã; Sinhá Braba: Dona Foaquina de Pompéu; $A$ vida em flor em Dona Beja; Gongo Socô; Chica que Manda (Chica da Silva); Chico Rei.

8. Ofício $\mathrm{n}^{\mathrm{O}} 127 / 77$, emitido pela Diretoria Geral em 4 de maio de 1977. Fundo: Ancine/Embrafilme, série 110.1/00297, Cinemateca Brasileira/SP.

9. Jean Bernardet ressalva o caráter ideológico em projetos do gênero, sobretudo em regimes autoritários, como era o caso brasileiro. Ainda assim, reconhece que somente o fato de inscrever um projeto em edital governamental não faz dos rea- 
lizadores do filme ideólogos da ditadura (Bernardet, 1982: 57-62).

10. Fundo Ancine/Embrafilme, série 110.1/00412, Cinemateca Brasileira/SP.

11. Idem.

12. Conforme projeto, a série apresentaria os seguintes capítulos: $1^{\circ}$ ) África; $2^{\circ}$ ) No navio negreiro; $3^{\circ}$ ) Marcha para o distrito do Ouro; $4^{\circ}$ ) Chegada e Revolução em Ouro Preto; $5^{\circ}$ ) Leilão; $6^{\circ}$ ) Mina e senzala; $7^{\circ}$ ) Quilombo; $8^{\circ}$ ) Gonzaga; $9^{\circ}$ ) Terror; $10^{\circ}$ ) Alforria; $11^{\circ}$ ) Riqueza; $12^{\circ}$ ) Dia dos Reis Magos; $13^{\circ}$ ) Ilusão (Fundo Ancine/Embrafilme, série 110.1/00474, Cinemateca Brasileira/SP).

13. A tradução juramentada deste documento data de 12 de abril de 1979. Fundo Ancine/Embrafilme, série 110.1/00474, Cinemateca Brasileira/SP.

14. As fontes são assim referenciadas: Maurílio de Gouveia: História da escravidão; Nina Rodrigues: Os africanos no Brasil; Jacob Gorender: O escravismo colonial; Arthur Ramos: $O$ negro na civilização brasileira; Roger Bastide: As religiões africanas no Brasil; Agripa Vasconcelos: Chico Rei; Frantz Fanon: Os condenados da terra.

15. Walter.doc, documentário dirigido por Beth Fomaggini e Luis Felipe Sá, 2000.

16. Depoimento de História Oral de Walter Lima Júnior concedido ao autor em 13 de junho de 2013.

\section{Idem.}

18. Diretor da TV Cultura, Herzog foi convocado a prestar esclarecimentos na polícia política, sendo divulgada sua morte pouco tempo depois de ter sido preso pelo DOI-Codi/SP. Oficialmente, alegou-se suicídio, sendo divulgada uma foto do preso enforcado em uma janela, prontamente rebatida como uma prova forjada.

19. Documentário Walter.doc, dirigido por Beth Fomaggini e Luis Felipe Sá, 2000.

\section{Fontes}

Filmes

CHICO REI. LIMA Jr., Walter. Embrafilme, 1985. VHS (115 min), son., color.

WALTER.DOC: o tempo é sempre presente. FOMAGGINI, Elizabeth; SÁ, Luis F. 4Ventos. 2000, $58 \mathrm{~min}$.

\section{Periódicos}

AZEREDO, Ely. Chico Rei, o mito negro. O Globo, 23 ago. 1987, Segundo Caderno, p.1.

BAZI, Sérgio. Chico Rei: o mito da conciliação. Correio Brasiliense, 13 mai. 1988, p.32.

CONVERSANDO sobre cinema: Walter Lima Jr. Revista Quadro a Quadro, ago. 1994.

CUNHA, Wilson. A difícil luta de Chico rei. Uma bela vitória. Fornal do Brasil, 27 ago.1987, Caderno B, p.4.

Fornal do Brasil,23 ago. 1987, Suplemento de
Domingo, p.24.
RACZ, George. Chico Rei: um grito de es-
perança e liberdade. Revista Visão, 26 ago.
1987, p. 22 .
TRÊS cineastas reivindicam seus direitos.
O Estado de São Paulo, 4 mar.1980, p.17. 
ALMEIDA, Juniele Rabêlo de \& ROVAI, Marta Gouveia de O. (orgs). Introdução à história pública. São Paulo: Letra e Voz, 2011.

AUMONT, Jacques. As teorias dos cineastas. $3^{\mathrm{a}}$ ed. Campinas: Papirus, 2004.

BACZKO, Bronislaw. Imaginação social. In: Enciclopédia Einaudi. Lisboa: Imprensa Nacional; Casa da Moeda; Ed. Portuguesa, 1985, v.5: Antropos-Homem.

BOSCHI, Caio César. Os leigos e o poder: irmandades religiosas e politica colonizadora em Minas Gerais. São Paulo: Ática, 1986.

BERNARDET, Jean-Claude. Piranha no mar de rosas. São Paulo: Nobel, 1982.

CHALHOUB, Sidney \& FONTES, Paulo. História social do trabalho, história pública. In: Perseu, São Paulo: Perseu Abramo, n. 4, ano 3, 2009, p.219-228.

DUARTE, Rosália. Cinema e educação. $3^{\mathrm{a}}$ ed. Belo Horizonte: Autêntica, 2009.

FERREIRA, Rodrigo de Almeida. Cinema, educação e história pública: dimensões do filme Xica da Silva. In: ALMEIDA, Juniele Rabêlo de \& ROVAI, Marta Gouveia de O. (orgs). Introdução à história pública. São Paulo: Letra e Voz, 2011.

Cinema, história pública e educação: circularidade do conhecimento histórico em Xica da Silva (1976) e Chico Rei (1985). Tese (Doutorado em Educação) - Faculdade de Educação, Universidade Federal de Minas Gerais, Belo Horizonte, 2014.

FERRO, Marc. Cinema e história. São Paulo: Paz e Terra, 1992.

FRIESEN, Joe. Canadá: a people's story as journalist history. History Workshop Fournal, Oxford, n. 56, 2003, p.184-203. Disponível em: <http://hwj.oxfordjournals.org/> Acesso em: 6 fev. 2011.

FRISCH, Michael. A shared authority: essays on the craft and meaning of oral and public history. Albany: State University of New York. 1990.

GOHN, Maria da Glória. Educação não-formal e cultura política. $3^{\mathrm{a}}$ ed. São Paulo: Cortez, 2005.

KORNIS, Mônica Almeida. História e cinema: um debate metodológico. Estudos Históricos, Rio de Janeiro, vol. 5, n. 10, 1992, p.237-250.

LAGNY, Michèle. Cine e historia: problemas y métodos en la investigación histórica. Barcelona: Bosch, 1997.

LERA, José Maria Caparrós. El cine como documento histórico, Revista Anthropos, n. 175, 1997.

LIDDINGTON, Jill. O que é História pública. In: ALMEIDA, Juniele R.; ROVAI, Marta. Introdução à História pública. São Paulo: Letra e Voz, 2011.

NAPOLITANO, Marcos. Fontes audiovisuais: a história depois do papel. In: PINSKY, Carla Bassanezi \& LUCA, Tânia de (orgs). Fontes históricas. São Paulo: Contexto, 2005.

Como usar o cinema na sala de aula. $4^{\mathrm{a}}$ ed. São Paulo: Contexto, 2008.

RAMOS, Donald. O quilombo e o sistema escravista em Minas Gerais do século XVIII. In: REIS, João José \& GOMES, Flávio (orgs). Liberdade por um fio. São Paulo: Cia das Letras, 1996.

REIS, João José \& GOMES, Flávio (orgs.). Liberdade por um fio. São Paulo: Cia. das Letras, 1996. 
RICOEUR, Paul. Tempo e narrativa. São Paulo: WMF Martins Fontes, 2010.

ROSENSTONE, Robert A. A história nos filmes. Os filmes na História. São Paulo: Paz e Terra, 2010.

SAMUEL, Raphael. History and television. History Workshop Fournal, Oxford, 1981. Disponível em: < http://hwj.oxford journals.org/> Acesso em: 6 fev. 2011.

SARAIVA, Leandro. Montagem soviética. In: MASCARELLO, Fernando (org.).
História do cinema mundial. $3^{\mathrm{a}}$ ed. Campinas: Papirus, 2008.

SERRANO, Jonathas \& VENÂNCIO FILHO, Francisco. Cinema e educação. São Paulo: Melhoramentos, 1931.

SOUZA, Marina de Mello e. Reis negros no Brasil escravista: história da festa de coroação de rei Congo. Belo Horizonte: UFMG, 2000.

VASCONCELOS, Agripa. Chico Rei. Belo Horizonte: Itatiaia, 1966.

\section{Resumo}

O objetivo deste artigo é analisar as interseções entre o cinema, a história pública e a circularidade do conhecimento histórico. As reflexões são desenvolvidas a partir do estudo do filme Chico Rei, dirigido por Walter Lima Júnior e lançado em 1985. Consideram-se as dimensões da história pública como espaço de produção e divulgação do conhecimento histórico em diálogo com outras áreas, não necessariamente acadêmicas. Problematiza-se o filme com temática histórica ante o saber histórico a partir da análise dos imaginários sociais presentes nos filmes, construídos na interface entre a historiografia e outros campos narrativos como a literatura, a música e o carnaval.

Palavras-chave: cinema; Chico Rei; história pública; circularidade do conhecimento histórico.
Abstract
The article intends to analyze the intersections between cinema, public history and the circularity of historical knowledge. The reflections are developed following the study of the film Chico Rei (directed by Walter Lima Jr., 1985). The dimensions of public history are considered as a space for the production and dissemination of historical knowledge, in dialogue with other areas, not necessarily academic ones. The film with a historical theme is discussed in view of historical knowledge following the analysis of the social imageries present in the films, that are built in the interface between historiography and other narrative fields such as literature, music and carnival.

Keywords: cinema; Chico Rei; public history; circularity of historical knowledge. 


\section{Résumé}

Le but de cet article est d'analyser les intersections entre le cinéma, l'histoire publique et la circularité de la connaissance historique. Les réflexions sont développées à partir de l'étude du film Chico Rei (dirigé par Walter Lima Jr., 1985). Les dimensions de l'histoire publique autant qu'espace de production et diffusion de la connaissance historique, en dialogue avec d'autres champs, non nécessairement académiques, ne sont pas négligées. Le film à thématique historique est problematisé en face du savoir historique, à partir de l'analyse des imaginaires sociaux préesents dans les films, construits sur l'interface entre l'historiographie et les autres domaines narratifs, tels que la littérature, la musique et le carnaval.

Mots-clés: cinéma; Chico Rei; histoire publique; circularité de la connaissance historique. 